\title{
SATURATION FOR CESÀRO MEANS OF HIGHER ORDER
}

\author{
LAURIAN SUCIU
}

Abstract. The classical Cesàro means of higher order are investigated from the point of view of saturation theory. In this direction the Cesàro means for power bounded operators were studied by Butzer-Westphal [1,2], and certain appropriate results were given by Lin-Sine [6]. In this paper we prove that the behavior of the Cesàro means of higher order concerning the saturation, are essentially of the same form, under the boundedness condition of Cesàro means. Also, some results of Lin-Sine are extended to Cesàro means of higher order.

Mathematics subject classification (2010): Primary 47A10, 47A35; Secondary 47B20. Keywords and phrases: Cesàro mean, Cesàro bounded operator, ergodicity, saturation.

\section{REFERENCES}

[1] P. L. Butzer And U. Westphal, The Mean Ergodic Theorem and Saturation, Indiana University Mathematical Journal 20, 12 (1971), 1163-1174.

[2] P. L. BUtZER Und U. WestPhal, Ein Operatorenkalkül für das approximationstheoretische Verhalten des Ergodensatzes im Mittel, in Linear Operators and Approximation I (Proc. Conf. Oberwolfach 1971; P. L. Butzer, J. P. Kahane and B. Sz.-Nagy, Eds.) ISNM 20, Birkhäuser Verlag, Basel, 1972, $102-113$.

[3] U. Krengel, Ergodic Theorems, Studies in Mathematics 6, Walter de Gruyter, 1985.

[4] J. W. G. Dotson, An application of ergodic theory to the solution of linear functional equations in Banach spaces, Bull. Amer. Math. Soc. 75 (1969), 347-352.

[5] L. Jones AND M. Lin, Unimodular eigenvalues and weak mixing, J. Functional Analysis 35 (1980), $153-166$.

[6] M. LiN AND R. Sine, Ergodic theory and the functional equation $(I-T) x=y$, J. Operator Theory 10 (1983), 153-166.

[7] W. Majdak, N. A. Secelean, L. Suciu, Ergodic properties of operators in some semi-Hilbertian spaces, Linear and Multilinear Algebra, published online 29 March 2012, 1-21.

[8] H. C. RÖNNEFARTH, On properties of the powers of a bounded linear operator and their characterization by its spectrum and resolvent, Thesis, Technischen Universität Berlin, D 83, Berlin, 1996.

[9] J. C. STRIKWERDA AND B. A. WADE, Cesàro means and the Kreiss matrix theorem, Linear Algebra Appl. 145 (1991), 89-106.

[10] J. C. Strikwerda And B. A. Wade, A survey of the Kreiss matrix theorem, Linear Operators, Banach Center Publications 38, Warsaw, 1997, 339-360.

[11] L. SucIu, Ergodic properties for regular A-contractions, Integral Equations and Operator Theory 56 (2006), 285-299.

[12] L. SucIU, Ergodic properties and saturation for A-contractions, Operator Theory 20, Theta Series in Adv. Math., 2006, 223-240.

[13] L. Suciu And J. ZemÁneK, Growth conditions and Cesàro means of higher order, submitted, 1-31. 